\section{THE MORTON LECTURE}

\author{
CANCER AND CANCEROUS DISEASES. \\ Delivered at the Royal College of Surgeons of England on Friday, \\ November, 11th, $188 \%$. \\ Bx Sir JAMES PAGET, BAkT., F.R.C.S., F.R.S.
}

W a may safely believe that Mr. Morton, in generously founding this lectureship, entertained the hope that it might lead to some distinct practical utility, perhaps even to the finding of a method for either the prevention or the care of cancer and cancerous diseases. I hardly need say that we have none yet. Where or how may we hope to find one? We are bound to search everywhere and in all ways; but in one lecture I can speak of only one way, and it shall be that which seems to me the most hopeful. I think that we may justly hope to find a remedy in the constant careful stady of the likeness of these diseases to others of which we already have means of useful treatment. We may be the more hopeful because the nearest likenesses of cancer and cancerous diseases are to $t$ wo other groups of diseases concerning which there have been, in recent times, very useful additions to our knowledge. In one direction we have their likeness to the simple or innocent tumours, in the surgical removal of which the risk of life has been diminished, even while the range of operating has been increased; and in the other direction we have their likeness, which I believe to be much more intimate, to some of the specific and micro-parasitic diseases, a group in which there has been progress towards both preventive and remedial treatment. It is of this last relation that $I$ propose especially to speak ; and I shall try to show that it indicates the method in which cancer and cancerous diseases should be studied more thoroughly than they usually are.

Let me say that I purposely speak of "groups" of diseases. I would not attempt to define what shall be called tumours, whether innocent or cancerous, or what diseases shall be called specific. I would rather undertake, if it were necessary, to show the inaccuracy or insufficiency of any definition yet given. Definitions, if they are to be more than convenient helps to arrangements, belong only to sciences more exact than pathology can yet be. It is better, at present, to think of diseases as in groups with borders that are not clearly marked : or, as of nations with ill-defined frontiers, and with inhabitant intermingling and even intermarrying. We may find typical examples of diseases as of peoples; it will be from such examples that I shall take my illustrations; and these typical examples we may -describe and may call them by distinct names; and these names are convenient for nomenclatures and for registration, for indexes and catslogues; but we must use them very cautiously in the real study of pathology.

Cancer and cancerous diseases agree with the simple or innocent tumours, such as the fatty tumours and overgrowths, the fibrous and fibroid, the simply cartilaginous, and the like, in that they are all growths, structures growing with some degree of likeness to the natu. ral structures of the body, especially of the part in which they are placed, but growing as if with a self-possessed power of maintaining and increasing themselves. With all tumours alike this growing is so far dependent on external conditions as is that of the natural structures; but it is not, as theirs is, in evident adjustment to the plan of other parts, and is not subject to the general control which, in health, keeps each part in useful association and concurrence with every wother.

This peculiar method of growing, purposeless and, as one may say, useifish, is characteristic of both innocent and cancerous tumours; and lit seems to indicate a very close affinity between them. It is rarely seen in any other disease than these and some specific diseases to - which I shall again refer. It is in some measure imitated in the eheloid growths of scars, and in the excessive callus sometimes formed in the repair of fractures; but these usually, after some time, cosec to grow, even though they may show no sign of dying or degeneracy.

Another indication of the relation between the innocent tumours and the cancerous appears in that it is impossible to mark any fair ibeundary line between them. Between such as may be deemed typical axamples of each, say a common fatty tumour and a cancer of the trectam or of the tongthe, there seems no likeness, except that they all wenter the manner I have spoken of. In all the rest of their life[1403] histories it would be hard to find two diseases more unlike; and yet the space between them and between all the innocent tumours and the cancers is filled with examples of intermediate forms; with sarcomata in all degrees of structural likeness to the one or the other, and with less or more of the characters of malignancy, the degree of malignancy usually corresponding with the degree of unlikeness to the natural structures. But this gradation is, as I have said, only what we find in all groups of diseases ; and if, on the one side, we cannot exactly define innocent tumours from cancerous, so, on the other, we cannot define them from the many forms of mere overgrowths which are not distinctly purposive, such as fatty growths about the neck, and en. larged prostates, thyroid glands, and the like.

The resemblances between the innocent tumours and the cancerous may seem to indicate so close relation that they ought to be regarded as of essentially the same nature. But I believe that an unlikeness indicating differences yet more essential may be observed in them, and it is expressed in our calling them severally innocent and malignant growths. Malignant is nearly synonymous with cancerous; and though the name is sometimes treated with disrespect, as being figurstive and without scientific meaning, jet, as an expression of certain qualities shown in the method and course of the diseases to which it is applied, it is neither unfit nor, I think, un. meaning. For the qualities which the name "malignant" indicates are far more distinctive, more surely diagnostic, of this group of diseases than are the minute structure and chemical composition of the diseased parts, or even than the method of their growing; and in this is an example of what we must hold in th9 study of all diseases, for pathology is a part of biology, and not derived chiefly from the study of anatomy and chemistry.

The life-history of diseased parts and growths, the shapes that they assume their construction, their changes as they grow, develop, or decsy, the modes in which they extend, or ulcerate, or die, their products, their influence on adjacent and on distant parts, and on the whole economy-all these things, in so far as they are not dependent on evident structure and locality, are true signs of essential variation of material composition. They are the signs of the very nature of the diseases in which we observe them.

It is thus with morbid as it is with natural structures, and, indeed, with all living organisms. The characteristic shape, construction, and manner of life and work of each species, or even of each individual, indicate natural qualities and affinities more specific, and of which the manifestations during life are more distinctive, than are any others that we can discern. I would, therefore, not discard the name "malignant." It tells with emphasis, yet not falsely or with exaggeration, the general biological character of the whole group of cancers and cancerous diseases, and it may keep us in mind that it is by these biological characters more than by the histological or the chemical, so far as these can as yet be discovered, that their affinities to the innocent tumours on the one side, and to the specific diseases on the other, may be judged.

In indicating the relations between the cancers and cancerous diseases and the specific diseases, I shall assume, as I did more than thirty years ago, when I was lecturing here on this same subject, that we usually mean by specific diseases those in each of which the phenomena of common diseases, that is, of such as might be produced by various injuries or external irritations in any healthy person, are modified in some constant and definite manner which gives them what we call specific characters. Every year's study since that time has made it more probable that what was then scarcely more than theory is now a sure general truth, namely, that each specific disease is due to the influence of a distinct morbid substance on some part or parts at which the characteristic signs of the disease can be and are manifested. Two conditions must coincide in each; the one general or diffused in a morbid material in the blood; the other local, in some part with which this material produces disease.

I use this vague term "morbid substance" on purpose that I may not pretend to definition or exact description. The reasons are, in. deed, constantly increasing, for the belief that each of many specific diseases is due to morbid changes produced directly or indirectly by a distinct, species of minute parssite, a microbe, a bacillus, or some other vegetable of lowest organisation, yet specific; as specific as any of the species much more highly organised. I believe that micro-parasites ( $r$ substances produced by them will some day be found in essential relation with cancers and cancerous diseases. Mr. Ballance and Mr. Shattock have, indeed, lately failed to find any; and if, in such a question as this, negative evidence could prove a negative, certainly theirs might make us hopeless. I would not be so; especially if workers so earnest and so skilful as they are will continue the search; but for the present it will be best to use such terms as morbid material, 
virus, or specific material, which, I think, we may be sure are at least not orroneous.

The specific diseases of which we believe and generally know thit they depend on morbid materials in the blood are very numerous-the aruptive fovers, many of the diseases of the skin, tetanus, hydrophobie, ague, and many more. They may be vaguely arranged in groups, each of which may include those which are most nearly alike and the group by which the conformity of cancers and cancerous diseases may be tested is one that includes, as its chief members, syphilis, tuberculosis, glanders, leprosy, and actinomycosis, each of which is known to have a distinct micro-parasito.

Lot me point out their most important general agreements. And, first, let it be observed that they are included by Virchow among tumours, under the name of granulomata ; and I doubt whether they can be justly excluded from the list for any reasons which would not equally justify the exclusion of many of the cancerous diseases. Certainly a tuberculous mass such as one may find in the brain, or a syphilitic gumms in a muscle, or, still more, an actinomycosis in the jaw, has more of the general characters of a tumour than any rodent ulcer has or many cancers of the lip or tongue. It is at least evident that all these specific, micro-parasitic diseases are, in their several mearures and in some of their forms, morbid growths and self-maintaining. All agree in this general character; they differ from one another in that each has a definite, characteristic, and diagnostic method of growing, as shown in its shape and in its substance, both tangible and microscopic, and in its relations to the structares which it involves. In these respects they differ from one another about as much as any of them do from cancer.

Besides, in all these diseases, as in the cancerous, the morbid growths are prone to special modes of degeneration, of partial decay and of death; and then they all tend to ulceration, each with a characteristic method, shown in the shape of the ulcer, the structure of its boundaries, and its mode of affecting the parts on which it oncroaches.

And all the cancerous and the others alike are at some time in. fective; some by inoculation, all by invasion of adjacent parts or by the transmission of materials, through lymph-spaces, lymphatics, or blood-vessels, to parts far off.

Now I venture to hold that likeness in characters so significant as these is evidence enough of essential likeness and of close affinity in all the diseases in which they are observed; and, therefore, that as we know that in tuberculosis, syphilis, leprosy, and the rest, there is for each a specific morbid material in the blood, so we should believe that there is at least one in cancer and cancerous diseases. The fact that it has not yet been found is not sufficient to prove that it docs not exiat.

Wo should observe here the same rule as we do in other groups of specific diseases. For example, among specific fevers so-called there is a similar general likeness, and they are regarded as a separate group or genus, call it what we will; and in this group there are many different fevers, each of which, though in many things like the others, has special and diagnostic characters, chiefly in the places, whother skin or glands or any others, in which it shows its local characters. Of many of theso fevers wo know that each is associated with a different morbid material in the blood, a micro-parasite or whatever it may be ; of the rest, we do not know this, but we do not doubt it; we are as sure of it as of anything in pathology not cer. tainly known. So may we be, I think, that cancer and cancerous diseases are specific in the same sense as are those other diseases to which I have shown their general likeness. There are some unlike. nesses between them; cancer cannot be inoculated, it is not contagious ; but these are negatives. I believe that there are no positive generic unlikenesses; and as to the differences among them, the diseas9s that are certainly specific do not differ more from cancer than they do from one another.

Let me note also one more likeness among all these diseasesnamely, that as we see them in practice, we cannot but observe de. grees of conformity to what may be regarded as the typical forms of each. Just as I said that there are all degrees of transition from the innocent tumours to the cancerous, and to the mere overgrowths that are hardly abnormal, so are there all degrees of less or more malig napcy. And, similarly, we may trace all gradations from the typica tuberculosis, through the less or more of scrofula, to what some call mere delicacy of health; or we may trace syphilis till we doubt it existence, or guess at it in some combination with scrofula or gout

But now, that I may illustrate the influence of different kinds of virus in the production of morbid growths, let me point to some of those occturring in plants.

The whole study of tumours may, indeed, find admirable illustra- tion in regetable pathology. For example, I think that some of the best evidences, even nearly the proofs, of the truth of Cohnheim's explanation of the origin of tumours, at least of the innocent ones, from portions of germinal tissue remaining undeveloped, may be seen in some of the xylomata or woody tumours which may be found on trees, especially on beeches and cedar-trees; for in these it is often evident, and always probable, that they have grown from buds, or "sleeping eyes," as they have been called, which have remained for a time dormant, inactive, enclosed within normal structures, and then have, as it were, awakened and grown, after a manner of their own, with good woody tissue, but separate and purposeless. Our museum has specimens of such tumours-oval or nearly spherical masses of hard wood, well defined, concentrically laminated, either lying just beneath the bark of the branch or trunk in which they have grown, or nearly separated and cast out. Some of them, like polypi or exostoses, have pedicles continuous with the proper wood of the tree, and some have little outstanding twigs or branchlets, outgrowths from the buds in which themselves had their origin.

And if these and the vast number of growths of the same kind observed in plants may illustrate the apparently spontaneous production of the innocent tumours from germinal structures delayed in their development, so may galls illustrate the influence of a virus in exciting morbid growths. They may, indeed, illustrate both the conditions requisite for the manifestation of a specific disease-the specific morbid material and the part appropriate to its morbid influence.

Of these galls, which may fairly be called heterologous growths, as the xylomata may be called homologous, there are more than : thousand forms already known, and each form is produced by a different material, a different specific virus, as we may safely call it, inserted by a different species of insect in a leaf or some other part of a plant. The very nature of the virus, which is usually inserted with the insect's egg, is, I think, unknown ; but so constant are its properties, and so exactly defined, that the specific characters of each insect are not more invariable than are those of the galls which it has made to grow. As we may describe the specific characters of each insect, 80 may we those of its appropriate gall; and so may we, therefore, speak of each form of gall as due to a specific virus. This is especially seen when different kinds of virus are inserted in similar textures, as when one finds three or four different galls produced by as many different insects on the same leaf.

The oak leaves which I have here show these facts well. I am indebted for them to Mr. Rolfe, of the Royal Gardens at Kew. Here are, as he has written, ten branchlets of the common oak, and their leaves bear, altogether, ten different forms of galls produced by ten species of insects ; two, three, or four forms being on each leaf. The only variation shown is in some spangle.galls formed on the leaf of a variety of the common oak, which are distinguished by their purple colnur, but not by any apparent difference of structure.

Many of the galls are small, and may seem to you comparable with mere pustules formed of little more than disturbed natural structures; but they are not so; they are all outgrowths, in evident continnity with the natural structures, yet difforent from them, often very different. And this is more plainly seen in the larger kinds of gall, each with its well-defined characteristic shapo and construction, and its minute structures differing from the healthy structures with which they are continuous, as widely as do cancerous structures from those of the parts in which they grow. And it may be observed that in all, whether small or large, the specific differences are marked by shape and pattern and other large characters more than they are by ang minute structures as yet discerned.

I will not be tempted to go further in this intensely interesting field of pathology. I wish I could provoke some to pursue it, some who would study it pathologically with the same care and skill as Mr. Rolfe and others have studied it as a part of natural history. It must suffice now to have shown in it how certainly each of a large number of morbid growths, each as heterologous, each as specific as that seen in any cancer or cancerous disease, is produced by the influence of an appropriate specific virus.

There is, however, one point more which I must mention, for it may help to show that even a well-defined virus can produce its appropriate disease only in some exactly appropriate place or texture. Each insect, with an instinct as unfailing as any natural law, de. posits its egg and its virus in the leaf or other part of the very plant in which the right kind of gall can be formed. Each virus requires, as we may say, a susceptible and fitting place and substance; and this is a fact confirming what we believe in the case of many specific diseases, and as I venture to say in the cancorous. The two conditions must co-exist-the specific material, microbe, virus, or what ever wo may name it, in the blood which will carry it to every part, 
and the one appropriate part, texture, or place in which this material can produce the disease.

Now this part may be so small or so ill defined, it may seem so absolutely limited, as to give to the cancer when first found an appearance of being a merely local, a wholly local, disease ; especially as the general health may be undisturbed. It may be called local, in the sense that it is in the only one locality in which it can be formed, but the analogy of the specific diseases gives reasons for believing that it would not have occurred in this place unless there were a specific material in the blood which was carried to it; even as a gall would not form without the insect's puncture. And the like is evident in many specific diseases in which the presence of a morbid material in the blood is most certain.

For example, tetanus is due to a well-ascertained bacillus, and in the blood this, or some material produced by it, is carried to every part ; but it seems harmless to all till, after it may be some considerable time, it affects some portion of the spinal marrow.

In hydrophobia there is a specific virus, inoculable, probably a microbe ; it is everywhere diffused in the person or animal in whom it has been inserted; it is in the saliva and, it is said; may pass even to the foetus in a pregnant woman, or the milk of one suckling; and thus it may be during a period of good health; but at last it produces definite disease at the appropriate nervous centre.

In the sequels of fevers, where we cannot reasonably donbt that morbid materials remain in the blood, it is only in certain parts that diseases may be manifested. Thus, after scarlet fever it may be only in the tympanum or the lymph.glands; or after typhoid fever, in some cases only in portions of periosteum, in others only in a testicle or in a small portion of one vein, or of the spinal marrow. These last are, indeed, very illustrative cases. After all the signs of typhoid fever have passed away, when the convalescence is established, and all the waste and damage of the disease are being repaired; while thus, in respect of general nutrition, the health might be deemed above its average, we may find an acute inflammation of one portion of the periosteum of one bone. It is surely an evidence that that one portion was the only portion of the body in and with which the something in ... $\mathrm{h}^{\mathrm{l}}$ nod could generate disease. It seems the more evident in the fact than sometimes the periostitis has appeared symmetrically on both the tibiæ. The two portions of periosteum symmetrically placed were identical in composition, as symmetrical pieces of the body often are; therefore both were similarly disturbed; no other part being exactly like them, wo other was disturbed. In all the body nothing was susceptible of the disease except these two pieces.

Such facts as these deserve very thoughtful study, as evidences of the exceeding fineness of the differences among different parts of what seems to us the same structure. If a diseased process-say a syphilitic eruption-is evident on one portion of skin, and not on another, it is an evidence that these two portions are not exactly alike. Whether the difference be in structure, or in composition, or in relation to the nerve force, it may not be possible to tell; but there is a difference ; they are not exactly alike, though they may appear so to every test but those of disease. The evidence is of the same kind as that by which a chemical test determines the difference of two solutions; only the test in pathology is far more delicate.

Now these considerations have a definite bearing on the question of localisation of cancer. There may be the appearances of perfect health ; some have even thought that cancer is due to a kind of overflow of health; and, certainly, there is no greater fallacy than to think that, in its early stages, it is indicated by a cachexia ; yet, with all this general health, the specific morbid material may be in the blood. If there be in the body a part, however small, which is susceptible of cancer, this may become cancerous; but we may fully believe that, if this one part had been as insusceptible as all the rest, the morbid material would have remained in the blood harmless and unobserved. Such things are sure in some of the specific ctiseases. Syphilis may reappear after years in which no sign of it could be found ; or malarial fever may be for years dormant till, with some accidental disturbance of the health, it may be renewed with its specific characters unchanged. In both cases we must believe that some morbid material remained inactive and apparently harmless in the body.

In a large number of instances we have, I think, no knowledge of the reason why the evidences of any specific diseases naturally appear in one part of the body rather than another; no knowledge of the reasons for the different powers of resistance or self-maintenance in different parts. We cannot tell why small-pox is especially manifested at the skin, or typhoid fever in the Peyer's follicles, or tertiary syphilis in a piece of periosteum or muscle. But in all specific diseases, and in cancers more than in any, parts are cendered apt to become the seats of diseases after injury, or in degeneracies, especially those produced by long continued irritation. Thus cancer increases in frequency with the advance of age and of senile degeneration. Its frequency in the breasts and the uterus before old age coincides with what may be deemed their early senile changes when they cease to bo capable of their proper purposes. So, too, all cancerous diseases are apt to form in parts congenitally defective; and still more they follow iujuries, sometimes vory quickly. More commonly still they appear in parts that have long been the seats of some "irritation," as we call it, as in the scars of burns, or in syphilitic tongues, or gums, or cheeks irritated by bad teeth, or in lips irritated by pipes, or tongues by hot tobacco smoke. Similar to these are the soot cancers, and the petroleum cancers, and those of the abdomen and thigh, which are seen in Cashmir, in consequence of wearing a hot brasier over these parts.

Now, all these facts have led to our speaking of parts " becoming cancerous," and the term has, I think, been by some taken as implying that the beginning of a cancer is altogether local, and that the textures of a part may, as it were, of themselves, or through some common irritation or degeneracy, or in the course of syphilis or other diseases, change themselves and become cancerous-change, that is, their whole nature and mode of life from that which is common to that which is specific, or from one specific method to another. Bat this is far from being a fair deduction from the facts ; for all these irritations and degeneracies are in many persons ineffective, and the facts observed are quite consistent with the much more probable belief that these degenorative changes only make the parts less able to maintain themselves, less able to resist the invasion of any morbid material in the blood which is brought into contact with them.

Here is, indeed, another likeness of cancer and cancerous diseases to the chief specific diseases. An injured part may become the seat of syphilitic disease, but this can be only in a syphilitıc person; or of tuberculous disease, but only in a tuberculous person; or of gout in one gouty; and even small-pox may be coufluent at an injured part though discrete at every other. Thus, in diseases recognised as specific, in those that certainly have a specific morbid material in the blood, we recognise a local injury or irritation as making a part susceptible, or apt for the manifestation of the specific morbid changes. So should we think when cancerous disease appears in such an injured or irritated part; and if are to speak of such parts as becoming cancerous, it should only be with the understanding that they are becoming likely to be the seats of cancer if there be the other conditions required for that disease.

Really, to suppose that any previously healthy part could, of itself. or in direct consequence of any ordinary change affecting it alone; so definitely alter its method of life, its shape and structure, its manner of growing and degenerating, as to become cancerous; and, still further, to suppose that all parts, however unlike in health, could change themselves into likeness as cancers; all this would be to assume more than can be matched in all the range of sure pathology or of natural history.

And the difficulty is not diminished by observing that the change is wrought in embryo structures. Embryo cells or protoplasms can no more of themselves change their destination, or by any common force be driven further from it, than any complete structures can. In so far as the destiny of germs and other embryo structures is not ab solately determined by inheritance, it is determined by their environment; they may be assimilated by furce of the structures next or near to them; and if these structures be cancerous, the embryo structures may become cancerous; but to assume that such shapes and modes of life as we see in the tuberculous, the leprous, or the cancerous diseases, can be self-assumed by embryo structures or by protoplasms, is scarcely less than to assume that an embryo gland might of itself change its destiny; so that an embyro liver might become a lung.

$I$ could, indeed, imagine that in the hereditary transmission of cancer there might be transmitted such a tendency to likeness to that part of a parent or ancestor which was cancerous, that the same part in the offspring might, as of itself, become cancerous; but, even if this were sure, it would not explain the numerous cases in which the cancer in the offspring is not in the same part as it was in the progenitor, or those in which many members of one family have cancer in many different parts. To explain these we need to aseume that there was transmitted a tendency to the production of the canoerous material in the blood; indeed, it would be hard and unfair to think that one tendency would be transmitted without the other. If both are transmitted we may well suppose that cancer would form somewhere; but really one can!be only guessing at questions such as these.

The fact of frequent inheritance is sure in this as in many other diseases, but its method is so mysterious; it is so utterly impossible 
to conceive the form or the material in which the impregnated ovum contains that which will become or be made cancerous, that it cannot be safe or useful to think that we can deduce anything from the bare fact. We are apt to speak of potentiality, tendency, and predisposition as if they were forces independent of matter or of structure; but when we try to think of the very things on which they depend, wo find ourselves in a cloud-land of mystery where the difficulty of discovering truth is as great as the facility of guessing.

I have limited myself to the pathology of primary cancer and cancorous diseases, and I shall not go far beyond it ; for nearly all that happens in the history of secondary-or, as they are now wrongly called, metastatic-cancere, or of some that recur after operations, might happen as consequences of that which was at first an entirely local disease: If we could believe a primary cancer to be formed by any part in and of itself, then it would be easy to believe that this cancer wonld infect adjacent structures, and that materials would be carried from it in the lymphatics and the blood.vessels, and would grow and multiply in distant parts, and in them be centres for yet further infections.

But I hope that I have shown reasons enough for believing that primary cancerous growths are not merely local diseases, but require for their production at least the two conditions that I have spoken of. Once formed, the secondary diseases and much of all that follows, even to the inevitable end, may be due to transference of cancerous materials from the primary growths. But I do not think that all the secondary and yet later events can be thus explained. We have no reason for believing that the morbid material in the blood is always exhausted in the formation of the primary cancer, and it seems more probable that, in some form, this material remains or is renewed, and that to this, as well as to transference from the primary disease, the secondary and later changes are to be ascribed. I believe there are facts in the history of secondary cancers which cannot be explained by the merely mechanical processes of penetration or of embolism. There are often evidences of other than mechanical relations between the primary and secondary. The organs that are most frequently the seats of primary cancer are very rarely the seats of secondary. The nterus seldom becomes cancerons in one who has cancer of the breast; still more rarely does the breast become cancerous as secondary to the uterus; and I suppose no one ever saw two cases of cancer of the face or lip or any part of the digestive canal following cancer of the tongue. Then there are the well-known cases of cancer of the thyroid in which the secondary disease affects, as if by selection, the bones more often than any other part. And my son has gathered facts from the records of great numbers of cases of cancer which seem to indicate that the relations between the primary and the secondary seats of cancer may be compared with those which he found between the primary and secondary seats of suppuration in pyæmia. Certainly, some of those relations-such, for example, as that between the peritoneal and pelvic organs and the parotid gland-could not be explained by any meohanical embolism. Similar relations, I think, will be found between the primary and the secondary and later seats of cancer.

But I shall not discuss these questions; the main interest of the whole subject is in the biology of the primary cancer or cancerous diseases, and I hope I shall be deemed to have shown that in this, as in all the other characters of which I have spoken, there is so great likeness and so little unlikeness between these diseases and the specific with which I have compared them, that we may expect equal generic likenessin respect of the material on which they essentially depend. If it be so, then we may justly hope that by careful study, both clinical and experimental, we may find the morbid material, microbe, or ptomaine, or one or more of their products to which cancer is due. And if this be attained then may we hope to be much nearer to a remedy, preventive or curative.

It would be easy to ask questions which this theory of the specific nature of cancer conld not yet safely answer ; to raise doubts which might seem to show it erroneous or insufficient. It may be asked : Why, then, is cancer not inoculable? Whence does its micro.parasite come? Why cannot it be found? Can one micro-parasite produce so various forms of disease? Where, in the unbroken series between innocent tumours and cancers, does the parasitic influence come in ? I could not answer these questions. I could ask many more just like them ; but I can remember that, when I last lectured here on this subject, if similar questions had been asked concerning tuberculosis, leprosy, tetanus, or many other diseases now known to be dependent on parasitic or other specific materials in the blood, they could not have been answered; or, most probably, those which would then have been answered "No" would now be more correctly answered "Yes."

And now it may be asked, if all these things be in due time proved, what. will the practical utility be ; what the better treatment of cancer?
I cannot tell. I promised only to suggest how best we might try to find out, and at least we may hope for more than is gained by the merely local operative treatment.

I should have tried to deal with this, but that the whole subject is so thoroughly and so admirably treated by my friend and former pupil, Mr. Butlin, in his recently published work on the Operative Surgery of Malignant Disease, that I could not in even many lectures have taught so much as he does; but it is clear that, great as is the good that operative surgery may do when practised with the prudence which he urges, it does not do all we want; the disease returns after even complete removal of the diseased parts. All that is locally wrong may be removed, the local portion of the disease may be deemed cured, but something remains, or, after a time, is renewed, and similar disease reappears, and, in some form or degree, is usually worse than the first, and always tending towards death. It is true that, in less measure, the like of this may be observed in some of the cases of specific diseases which appear medicinally cured. Ague may have been cured, as we say, with quinine, or syphilis with mercury, and for years no sign of either may have been observed, but sometimes one will reappear in its old form, or as modifying some other disease: Especially we may see this in persons who have suffered with ague, or any similar kind of malarial fever, or even without suffering from it have been exposed to the malarial poison. They may have been in good health for any number of years, but the ordinary changes following any considerable operation may bring out some dormant material, and all the characteristic signs of the fover may for the first time appear, or may be renewed, and may be cured, as we say, with quinine.

Still, we might well be nearly content if we could find a medicine as efficient against cancer as mercury and quinine are against syphilis and ague, especially as the recurrences of these diseases are less, not more, severe than the primary. Such an one we have not. Can it be reasonably hoped for? Yes, and the more so if we may countcancer among the specific diseases, for it is of some of these that we most surely have remedies more nearly complete than we have of any other disease whatever. The name commonly used of specific medicines may tell this. There are none so definitely useful against diseases of any other kind; and, indeed, if we had to reckon cancer as a local disease, we should have to look for a different remedy for it in each locality.

But I can now only commend the study to my juniors. It must be both clinical and experimental, and probably the latter will be the more fruitful. If once the specific morbid material can be found, it may be dealt with as others generically like but specifically unlike it have been. But I will not guess how. I have tried to show by facts a right way to a good end : I will not now by guesses run the risk of pointing to a wrong one.

\section{BRITISH MEDICAL ASSOCIATION, FIFTY-FIFTH ANNUAL MEETING.}

PROCEEDINGS OF SECTIONS.

ON A NEW TREATMENT BY ELECTRICITY OF PERIUTERINE INFLAMMATION - (PERIMETRITIS, PARAMETRITIS, PHLEGMON, CELLULITIS).

Read in the Section of Obstetrics at the Annual Meeting of the British Medical Association held in Dublin, August, $188 \%$.

BY G. APOSTOLI, M.D., PARIs.

Translation by WM. WOODHAM WEBB, M.D., M.R.C.P.L.

Gentlemen; - The important subject of peri-uterine inflammation in which the prognosis is so difficult, the consequences are so serions, and the treatment is so uncertain, brings before us some of the most perplexing problems in gynæcology. Only too often does it happen that the futile efforts of the surgeon to give relief to his patient, by the application of all his medical resources, exhaust his own ingenuity and try to the utmost her endurance.

It may truly be said that perimetritis is the point noir of gynæcology. It is in the conviction that I may be able to throw some new light upon these difficulties that I venture, in a summary manner, to report to you the observations I have made, and what I have done in reference to them. Ever since the year 1882, when I began my study and treatment of fibroid growths, I bave carried on conourrently 